Article

\title{
Being Able to Play: Experiences of Social Inclusion and Exclusion Within a Football Team of People Seeking Asylum
}

\author{
Darko Dukic $^{1}$, Brent McDonald ${ }^{1, *}$ and Ramón Spaaij ${ }^{1,2}$ \\ ${ }^{1}$ Institute of Sport, Exercise and Active Living, Victoria University, Melbourne, VIC 8001, Australia; \\ E-Mails: darko.dukic2@vu.edu.au (D.D.), brent.mcdonald@vu.edu.au (B.M.), ramon.spaaij@vu.edu.au (R.S.) \\ 2 Department of Sociology, University of Amsterdam, 1012 WX Amsterdam, The Netherlands \\ * Corresponding author
}

Submitted: 31 January 2017 | Accepted: 6 April 2017 | Published: 29 June 2017

\begin{abstract}
Australian policy makers and funding organisations have relied heavily on sport as a vehicle for achieving the goals of social cohesion and social inclusion. The generally accepted premise that sport includes individuals in larger social contexts, and in doing so creates positive social outcomes, remains largely untested and uncontested. This article considers the ways in which playing in an asylum seeker football team, located in Melbourne, Australia, facilitates both inclusive and exclusive experiences for its participants. Drawing on ethnographic fieldwork, life histories, and policy analysis, this article identifies the often-ignored importance of a sporting habitus and physical capital in individuals' experiences of playing. The success or failure of the asylum seeker team to foster social inclusion is somewhat tenuous as the logic of competition can create conditions counter to those that would be recognised as inclusive. Further, such programmes are faced with sustainability problems, as they are heavily reliant on individuals within the organisation and community to "make things happen". However, we suggest that for many men, the asylum seeker team provides an important site for the development and appreciation of 'poly-cultural' capital that contributes to forms of resilience and the achievement of other indicators of social inclusion.
\end{abstract}

\section{Keywords}

asylum seeker; exclusion; football; inclusion; poly-cultural capital; refugee; sport

Issue

This article is part of the issue "Sport for Social Inclusion: Questioning Policy, Practice and Research", edited by Reinhard Haudenhuyse (Vrije Universiteit Brussel, Belgium).

(C) 2017 by the authors; licensee Cogitatio (Lisbon, Portugal). This article is licensed under a Creative Commons Attribution 4.0 International License (CC BY).

\section{Introduction}

In this article we focus on asylum seekers' experiences of social inclusion through their participation in an asylum seeker football team (henceforth referred to as the ASFT). In particular we aim to consider the individual and social conditions responsible for the various 'success stories' that emerge from the research. Central to the success narrative is the connection between the players and their lifelong engagement with football.

The ASFT was established as part of an initiative by the Asylum Seeker Resource Centre (ASRC), which is an independent, non-for-profit human rights organisation operating in the western suburbs of Melbourne, Australia. The ASRC was founded in 2001 in response to the lack of basic assistance asylum seekers living in the community were receiving. Initially a food bank, it extended its mission to include English language programmes, free legal services and advocacy, not to mention becoming a key platform in challenging the Australian government's asylum seeker policies. Since its inception, the charity has been growing from strength to strength, each year providing services for around 3,000 refugees and asylum seekers across 30 programmes on offer. 
The ASFT is one of the programmes offered, originally initiated by a weekly gathering of ASRC members at a public garden space for a social game of football amongst themselves. After gaining considerable interest, ASRC members attempted to form a team to enter competitive tournaments and leagues. The ASRC provided a volunteer coach and a team was established in 2012. In 2015 the ASRC managed to secure a partnership with the Brimbank City Council (local government) and acquired a home ground for the football team for an indefinite period. The pitch is located in Albion and has a clubhouse, changing rooms as well as two regulation football fields.

The ASFT competes in an amateur, 'home and away' style football league governed by VicSoccer, a privately run organisation targeting amateur football clubs in Victoria and operates outside the jurisdiction of Football Federation Victoria, Football Federation Australia and FIFA. In the 2016 season, the team competed in VicSoccer's Men's North-West Division 1, with matches played weekly on Sundays throughout Autumn and Winter. The league comprised of eight teams from the northern and western suburbs of Melbourne encompassing a variety of socio-economic spaces and locations. For example, in 2016 the ASFT competed against PEGS (an all-boys team from a private school in Melbourne's North-West), University of Melbourne (one of Australia's highest rated universities with a number of international and domestic students in the team located in Melbourne's inner suburb of Carlton), AZAAD Club (a Punjabi Sikh backed community club located in Melbourne's outer northern suburbs), as well as a variety of other mono-ethnic community clubs.

Mindful of Collins and Haudenhuyse's (2015) and Spaaij, Magee and Jeanes's (2014) observations about the dimensions of social inclusion and sport, we are interested primarily in 'inclusion through sport'; that is, the ways in which sport might facilitate asylum seekers and refugees' capacity to engage with Australian communities more broadly. From the outset we recognise that sport as a site for inclusion is problematic and the framing of this research similarly excludes in that it focuses on men who possess a certain level of physical capacity and skill. There are important considerations regarding 'inclusion in sport', and we examine these briefly through the concepts of sporting habitus and physical capital. However, our argument is framed through a surplus, as opposed to a deficit, model. That is, we are interested in those who successfully participate in the ASFT. In particular, we have adopted Mila-Schaaf and Robinson's (2010) Bourdieu-inspired concept of poly-cultural capital. Mila-Schaaf and Robinson developed the concept of polycultural capital through their examination of 'successful' (in terms of education attainment, employment, health measures) Pacific Islanders in New Zealand society. Notably poly-cultural capital is demonstrated through the "maintenance of Pacific values, cultural pride, Pacific language fluency and acceptance from Pacific peoples and others" (Mila-Schaaf \& Robinson, 2010, p. 14). McDon- ald and Rodriguez (2014) have demonstrated how playing sport, in the case of Pacific Islanders rugby, may create a space for the accrual of poly-cultural capital.

Rather than the incorporation of a minority into an exclusive (majority) group, social inclusion in this article should be understood as the ability of individuals to participate in the community (Donnelly \& Coakley, 2002). There are many ways that one might participate in the community and our argument regarding the ASFT is that it provides a vital space where those, who possess the particular football habitus, can establish the necessary self-confidence, resilience, and social networks (hence poly-cultural capital) to engage with the community in a way that doesn't necessitate the abandonment of one identity for another. We recognise that 'community' is an elusive and contested term that may largely be devoid of meaning (Delanty, 2009). Yet, as will be shown in this article, the term carries considerable meaning in everyday practice, not least for those who seek to navigate life in a new country. In the context of this study, 'community' primarily refers to the geographic area in which members of the ASFT live-the outer suburbs of Melbourne specifically, and Australian society more broadly-but also to the social groups they identify with and feel a sense of belonging to.

In the remainder of this article we contextualise the relationship between social inclusion and sport in Australia especially in regard to policy and practice, before briefly outlining the ethnographic approach to the research. Following this we examine the 'levels of inclusion' operating in the ASFT, centering our focus on the importance of possessing a football habitus, after which we discuss the problematic issues of competition and sustainability. Finally, we conclude by exploring some of the 'success stories' and the ways in which football may have contributed to them.

\section{Social Inclusion and Sport in Australia}

As with many other industrial nations in the West, Australian policies and attitudes toward refugees and asylum seekers have become increasingly punitive, restrictive, and hostile over the past twenty years (Cameron, 2013; Clyne, 2005; Every \& Augoustinos, 2007). The rhetoric of tough border control and detention ('turn back the boats'), threat to 'Australian values', and Islamophobia, has entered the political and media landscape, serving as a platform for not only right-wing political movements but also mainstream parties.

Since the new millennium, and arguably modelled on similar initiatives from the UK and Europe (e.g. Amara et al., 2004), both State and Federal governments have increasingly sought to use sport as a vehicle to assist in the integration and resettlement of migrants, refugees and asylum seekers (Cortis, 2009; Olliff, 2008; Spaaij, 2012, 2015). For example, the National Action Plan (NAP) to build on social cohesion, harmony and security (Ministerial Council on Immigration and Multicultural Affairs, 
2007), which was written in the context of increased fear of domestic terrorism, noted that to combat the increasing exclusion of "young members from some communities", "more active participation in mainstream sporting, social, and cultural activities" should be encouraged to "lessen feelings of isolation and marginalisation" (p. 13). The People of Australia: Australia's Multicultural Policy (Department of Social Services, 2011) similarly places sport as one of the five key initiatives or vehicles for achieving multiculturalism. The policy's Multicultural Youth Sports Partnership Program aims to "create connections and involve youth from new and emerging communities, and culturally and linguistically diverse backgrounds (including refugees and minor refugees), through sport and active recreation activities" (p. 8).

With the perceived value of sport participation dominating Australian sport and integration policies, National Sport Associations (NSAs), State Sport Associations (SSAs) and local government bodies were quick to adopt the governing logic, securing funding to run programmes and seeking to capitalise on the dual benefit of meeting strategic participation targets and accessing possible athletic resources, whilst assisting in building a healthy and cohesive multicultural society (Jeanes, O'Connor, \& Alfrey, 2014). There is no denying that sport in Australia is a "key site of culture production and social prestige" (Spaaij, 2015, p. 303) and some research demonstrates that sports programmes aimed at newly arrived populations can be important platforms for social capital, identity building, feelings of belonging, leadership and pro-social behaviour to occur (see Centre for Multicultural Youth Issues, 2007; Nathan et al., 2010, 2013; Palmer, 2009; Spaaij, 2012, 2015). However, whilst the rhetoric about the power of sport to act as a vehicle for social inclusion is strong, the evidence is largely anecdotal and there is often a conflict between policy and practice (Jeanes et al., 2014; Northcote \& Casimiro, 2009; Spaaij, 2013). For example, Northcote and Casimiro (2009) critically evaluated the application of the NAP to find that newly arrived migrants have a clear preference to engage in sport initiatives that are fluid and informal than the rigid and structured organised competitive sport that predominate "mainstream" sporting culture. Further there exists tension between policy makers and those organisations charged to enact these policies. As Cortis (2009, p. 94) observes in her research on culturally and linguistically diverse (CALD) women and sport:

Australian initiatives aimed at promoting diversity in sport have been largely aspirational and have taken a lower profile, lacking the legitimacy and co-ordination that a national social inclusion agenda, diversity compliance framework, or sports equity agency would provide.

National sporting bodies are risk averse and reluctant to invest on 'minimal return' (Cortis, 2009; Jeanes et al., 2014; Olliff, 2008). Therefore, their approach is mostly a top-down, one-size-fits-all model which ultimately strengthens some of the barriers (e.g. lack of inclusive practices and accessible targeted programmes, cultural misunderstanding of gender expectations, lack of access to transport) faced by new arrivals (Olliff, 2008; Spaaij, 2013). Northcote and Casimiro (2009) and Spaaij (2012) both identified that, in practice, the outcome for refugees and newly arrived migrants rarely equates to the policy rhetoric and can instead further disengage and alienate some youth.

While sport is viewed to have 'integrative power', integration is a heavily contested term and the definition draws large significance when used in broader sport policy discourse (Jeanes et al., 2014; Spaaij, 2012; Walseth, 2006). Jeanes et al. (2014) and Spaaij (2012) point out that the modern and systematic definition of integration is a collaborative and reciprocal process on both the part of the host society and the migrant, whereby the newly arrived have "the ability to participate fully in economic, social, cultural, and political activities while maintaining one's cultural identity" (Spaaij, 2012, p. 1519). The question remains, therefore, what are the required conditions to 'participate fully'? In most cases, sports organisations' inclusion framework can best be defined as the absence of exclusive policy, as if to say "we're an inclusive club, anyone is welcome to join and play". This position is more assimilationist than the integration perspective mentioned above: the responsibility falls on the individual to "fit in to" the existing sport model. Further, what are the effects of fitting in? Does this open up opportunities for greater civic participation?

The ASFT presents a model of sport inclusion that overcomes many interpersonal and structural barriers. The ASRC provides the team with all the necessary training and playing equipment, inclusive facilities and spaces, and in some instances they provide credit on their public transport (Myki) cards for commuting to and from football matches. On given days the centre will also have some healthcare professionals available, such as general practitioners and physiotherapists to treat any ASRC members. Certain players from the team would feasibly have experienced more difficulties to play in their native land. For example, many of the team members talked about playing in Iran as schoolboys in their flip flops, on narrow streets and with plastic balls, and hence they relished the opportunity to play on full-sized, grassy football fields and in their football boots.

Therefore, rather than focus on the undeniable barriers that exist for refugees and asylum seekers in gaining inclusion in sport, this study sought to identify whether, and if so how, those that were included, that were playing, experienced social inclusion through sport. In a way, by focusing on the ASFT, we were looking at those 'success stories', which individually might seem anecdotal, but collectively provided some empiricism to when and why sport might contribute to inclusive experiences. The next section discusses the research methods used to elicit this empirical data. 


\section{Method}

The data presented in this article was collected using an ethnographic approach (Madden, 2010). The primary author shared some common experiences with the ASFT members, namely that he had also once been a refugee (arriving in Australia in 1990) and had spent his formative years (both in the Balkans and in Australia) playing football on a daily basis, eventually making it to a semiprofessional level of competition in Victoria, Australia. Utilising this physical capital (as a football player), he volunteered as an assistant coach and doubled up as an outfield player for the duration of the 2016 season. It is through the 'doing' that the primary author engages with the field, and as such the researcher's body and his playing capacity allowed for a type of "observant participation" (Wacquant, 2004). Further, as demonstrated in a field-note later on in this article, he literally becomes 'one of the boys' on game day, a position that opened a significant opportunity for reflexivity regarding being an asylum seeker and his own personal trajectory in the Balkans and Australia. This on-and-off-the-field involvement allowed him to (1) use the body as an instrument in collecting sensual data which lead to (2) establishing a cross-cultural intimacy and trust with the ASFT members allowing the researcher (3) to learn from team members' interactions, relationships thoughts and attitudes (Evers, 2010). The season lasted approximately six months, inclusive of warm-up and competitive fixtures, with one training and match held per week.

A detailed field-note journal was kept by the participating researcher. Recording the field began from week one, with a focus on the relationships, moments and actions that shaped the space. As an active participant, these notes also included the researcher's experiences and embodied responses to the field. Journal entries focused mainly on two regular team events, namely training (which was mostly done with just the team) and matches (often at away venues and in interaction with the opposing team). Notes were taken during other related interactions with the field, for example, social gatherings organised by the Centre, team meetings and occasional post-match dinners at restaurants organised by the players themselves. This included incidental conversations, small talk and other social interactions.

Furthermore, individual, semi-structured, interviews were conducted and digitally recorded. The interviews focused on the player's experiences and involvement in the ASFT as well as what playing football means to them. Staff and volunteers who were involved in administrative aspects of the team, but did not play, were also given the opportunity to provide their views and opinions. Their perspective provided a broader analysis of the team's value off the pitch and as a whole. In total, nine interviews (with two staff members and seven players), lasting between 30 minutes and 1 hour, were conducted. All interviews were transcribed and participants were anonymised. The data were organised using thematic analysis and resultant themes emerged inductively, some of which we discuss below. The research for this project was approved by and complied with the requirements of Victoria University's ethics committee.

\section{Levels of Inclusion}

In exploring the characteristics and experiences that players in the ASFT had in common, it is possible to understand how playing in the team created conditions for inclusion into the community more broadly. It is important to note that not all experiences were positive or inclusive, that the sustainability of programmes such as this is tenuous, and that even within teams, such as the ASFT, there are varying levels of inclusion/exclusion. Nevertheless, we argue that the football experiences in the ASFT are centrally important in providing a social and physical space of belonging, or "safe space" (Spaaij \& Schulenkorf, 2014), from which members developed the resilience and capacity to engage with other communities.

\section{Football Habitus-Inclusion in the Team}

Football had been and continues to be an important component of the embodied histories of the men in the ASFT. Talking about their memories of playing as children and growing up elicited animation and happiness. Football was regarded with fondness and produced feelings of nostalgia. Almost universally, football had occupied large periods of daily life and had been their priority recreational activity, as the following comments suggest:

Everyday. Do you know why? Because when I finished school we go straight out and play. Before we go home we go play football. (Mejsam, late 30s, Iran)

Every single day for hours!...When I was a teenager I would play six hours a day. Every day! (Milad, early 30 s, Iran)

Two times a week for the school, and in the street, everyday. (Azizi, mid-20s, Iran)

Not surprisingly, the inadvertent by-product of so much time spent playing was literally the 'football habitus'. In other words, they could play, and in playing moved naturally below the level of conscious reflection (Bourdieu \& Wacquant, 1992). Indeed, others recognised the possession of the football habitus as a form of physical capital (cf. Shilling, 2013). Being able to play, to pass, and to conceptualise the game has a form of value, which gives one easy access to the field of play. The field of play is simultaneously a physical and a social space, and the football habitus can overcome the potential for misrecognition arising from the diversity of linguistic and cultural backgrounds that refugees and asylum seekers have. So, whilst the day-to-day negotiation of life in a new country is often fraught with uncertainty and full of misunder- 
standing, kicking the ball provided a space of familiarity, confidence and even freedom in the sense of movement and flow.

The 'football habitus' extends further than the physical action on the pitch. It is also expressed in the ability to talk about football with authenticity. Talking about football revolved around three major topics: European/English teams, domestic teams from one's home country, and the national team in relation to World Cups. Talking about football was also a central part of one's social interaction in the refugee and asylum seekers' home country. For example, Kigali from Rwanda explains to what extent his social experiences were tied with FC Barcelona, the football team he follows:

Yeah, that was also something that bound people together and that's when we used to catch up. If you want to catch up with your friend you say. "OK let's go and watch this game", and you meet somewhere and you have a coffee or something while you're watching the game and then you get up and you make the plan for the next game too.

Being able to talk about football in the context of the ASFT similarly recreated familiar social interactions. These interactions could be inclusive and exclusive. Thus, just as everyone could talk about FC Barcelona or Manchester United, conversations in Farsi about the domestic competition in Iran would limit one's capacity to engage.

For most of the members, playing football has been ever-present throughout their lives. With the exception of one, all the interviewees said they joined the team within months of arriving to Australia. Despite massive changes in their lives, for some, playing football has been the only consistent aspect. This is evident in their prioritisation of football even when they have "too many things on top of that".

When asked why he chose to play football in Australia, Fwayo, who arrived alone as a teenager eight years ago from Zambia, responded by saying:

I like soccer. It's my favourite sport and I needed something to occupy my free time, you know?...I needed to feel like I was doing something a bit constructive, something that I like and something that I enjoy.

Azizi, a man in his late twenties who had joined the team four years ago, had a similar response to the same question. He replied:

Because at the time I didn't have a job and everyday I would go to the ASRC for English classes, so I wanted to find a hobby for weekends....For me, living in Melbourne at first, I wasn't in the community and it was the worst days for me on the weekends, it was very boring. So the best thing to do on the weekends was to play football.
In the beginning, a lack of time or priority to play football was not a barrier for some members of the team. Azizi also spoke about initially feeling lonely and locking himself in his room in the government housing before he started the football programme. While some of them now had jobs and families, football still remained high in their priorities. The team manager Sam, who is an asylum seeker, had this to say about one of the players:

I feel amazed. They will have too many things on top of that, but always, for him or lots of other players, maybe they are not going to every training, but on Sunday they just say "ohh, I have to go to the match". This is their first priority. They don't think "today I can go somewhere else", no, they have to go to the match.

The combination of structural support offered by the ASRC and the football habitus of the members of the ASFT results in a programme that has a meaningful impact on the lives of these asylum seekers and refugees. The programme provides more than just a diversion from the liminal nature of day-to-day life. In many ways it becomes a space where resilience can be built (Johns, Grossman, \& McDonald, 2014), where one can tap into various resources, and connect with others through an activity that literally comes as second nature.

\section{Competition-Relationships of Power}

As mentioned earlier, the ASFT play in a home and away seasonal competition. The success or failure of the ASFT to foster social inclusion is somewhat tenuous as the logic of competition can create conditions counter to those that would be recognised as inclusive. Every weekend the ASFT are forced to negotiate new power struggles against teams with varying dispositions towards asylum seekers. This is a fact not lost on some members of the ASFT. Mejsam, who hails from Iran and is in his late thirties, had this to say about why he continues to play football for the ASRC team:

(What) I want to show to people, is that refugee people is not dangerous people or somebody who come by boat. But my experience, I think it was two years ago or maybe more, we played with a team...that team is so young; $20,23-24$, all of them, and we won the game. But when the game finished all their players come and shake our hand, "we are so glad to play with you" and I ask "why?" and they said "we had a bad background uhh thinking about refugee people, we think refugee people are angry people and fighting". That time I'm so glad we show the culture and we are not dangerous.

This type of interaction suggests ways that sport might transform attitudes about asylum seekers and refugees and in doing so open opportunities to break down some of the barriers that create exclusion in other spaces in 
society. However, these interactions are not always positive, and for every transformative moment there is another one where stereotypes and stigmas are reinforced. Regardless of whether the experience of competition is positive or negative, an "othering" occurs that the ASFT has little control over. Further, even in relatively "social" leagues, the priority to win is stronger in some teams than in others. Football, like most sports, often creates situations where aggression, violence, intimidation, and cheating are utilised as part of a tactical approach to winning at all costs. Often these types of tactic are intended to distract players from the game, and bait the opposition into reactions resulting in free kicks, or even yellow or red cards. The following is a field note from such a game:

Our opponents were particularly playing dirty and doing anything to provoke us, including cheap tackles and insults, both on and off the ball. They knew exactly what they were doing. Surprisingly the referee (who we had history with) was doing okay to manage it while still somehow being against us for all the important decisions. Still, he didn't seem nearly as bad as on previous occasions. Fifteen minutes into the second half, Mejsam got into a scuffle with one of their younger players while the ball was on the other side of the field. They had a hold of each other's shirts and I was worried a fight would break out. Again, this was very unusual. Mejsam is very mild mannered and always a true gentleman. To see him holding one of their younger player's shirts was baffling. Being the closest person to them, I sprinted to Mejsam's assistance and pushed the kid away from Mejsam in an attempt to break up a potential fight. As I stood between them, the referee adjudged retaliation on my part and showed me a straight red card. This was my first everred card in my entire junior and senior career. I was stunned. Both teams' players now ran to where the incident occurred and a full-blown melee ensued. Everyone was now pushing and shoving, and as I walked off the field, another red was brandished to someone in the pack. Dariush and Ehsan had surrounded the referee and were shouting at him imposingly. I quickly ran back to try and restrain my teammates from doing anything stupid. The opposition continued to fuel the fire by pushing and insulting us even though we had stopped paying attention to them a long time ago and were now firmly focused on abusing the referee. We had left him with no choice as he called the game off. Some of the opposition's older players were still shouting insults at us and claiming the moral high ground as we walked off the field. It was incredible. This is what they were instigating the entire game and they were hell bent on making it happen.

What this field note demonstrates is the way in which competitive, mainstream sport is surely a problematic vehicle to achieve social inclusion (Northcote \& Casimiro,
2009). Rich, Misener and Dubeau (2015) note in their analysis of a community cup in Canada, that successful inclusion is achieved through a variety of modifications (team size and make up, no goalies, smaller fields, one-off tournaments) to football intentionally away from the mainstream model. The sorts of aggressive interactions described above were not unusual. Frustrations, feeling hard done by the referee, even internal disagreements between teammates during matches (by-products of competition), all have the potential to derail the positive outcomes of playing. One may question the necessity of being part of a full competition season; however, it is the competition that many players held as important. The ASFT wanted to be part of the mainstream. In playing they had at least the opportunity to represent themselves in a broader public space. Further, even incidents like the one above had the effect of producing a sense of solidarity within the team and built stronger bonds between individuals from a diversity of cultural backgrounds.

\section{Sustainability}

The ASFT is designed specifically in the context of the needs and conditions faced by refugees and asylum seekers, yet exists within the format of mainstream competition sport. For the large part this has been a very successful programme, however due to its 'bespoke' nature it constantly faces issues of sustainability. This is primarily because it is heavily reliant on volunteers and individuals within the organisation and community to 'make things happen'. The basic logistics of week-inweek-out matches, uniforms, laundry, managing teamsheets, marking the lines on the field, transport and injuries usually fall to a few individuals. Over the long winter there are weeks when there are barely enough players to field a team, and other weeks when there are so many players that ensuring everyone gets a fair time on the pitch is almost a political undertaking.

The knowledge of how to do these things is developed through experience and, as a result, if key individuals leave for some reason then that knowledge often goes with them. Unlike roles (president, secretary, treasurer, etc.) at mainstream clubs which are usually elected positions complete with job descriptions, ASFT positions are largely ad hoc. Further, based on the Australian model, mainstream clubs generally have active histories, and hence identity, maintained by the members with long-time connection to the club and the community in which it resides. The ASFT does not have access to this type of historical identity, and the resources (volunteers, memberships, finances) that come with it. These resources might also include forms of social and cultural capital that other clubs utilise in order to maximise their connections to local communities.

Perhaps the most significant role at the ASFT is the manager, especially as it is through this position that the ASFT communicates its needs to the ASRC. Unlike most 
mainstream clubs, who operate as one organisation, the ASFT is part of a bigger organisation. Resources, both financial and physical, are available, but accessing them involves knowledge of who to ask at the higher organisational level. When procedural knowledge resides in individuals, then the success and sustainability of a programme such at the ASFT can suffer if individuals leave.

\section{Success Stories: Poly-Cultural Capital}

In spite of the potential problems raised in relation both to sustainability and the outcomes of competition, the ASFT is a successful vehicle through which asylum seekers and refugees experience forms of inclusion as demonstrated by individuals' participation in civic life. This participation takes various forms, for example undertaking further education (tertiary or technical), gaining employment, starting a business, getting a drivers licence, marrying, and something as simple as going out to dinner at a local restaurant with some teammates. Some players, based on their physical skill, moved on to play at more mainstream clubs, while others connected with clubs that had formed around ethnic identity. For example, several Iranian asylum seekers had moved on to play at an Iranian based club, and in doing so could connect to the Iranian diaspora in Melbourne, not only for football but more importantly resources, knowledge and support during their resettlement and search for employment.

These 'success stories', so to speak, revolve around two characteristics or themes. The first is social connectedness and the way the ASFT provides social interaction and support. The second is the way in which football facilitates the development of poly-cultural capital that strengthens elements of one's identity and contributes to the resilience and confidence required to engage with the uncertainty presented by the host country.

Social connectedness is experienced in a variety of ways and it is necessary to reiterate that that ASFT is only one of the many programmes offered by the ASRC. Programmes in themselves, however, do not create social connectedness. This connectedness comes about through what actually happens in these spaces. Football, by definition, is social because it requires one to engage with others. Creating opportunities for social connectedness is vitally important as recently arrived asylum seekers and refugees often experience intense isolation, uncertainty and loneliness. These conditions can be exacerbated by the long and unpredictable processing time for asylum seekers in Australia. ${ }^{1}$ Many newly arrived asylum seekers face a lengthy period of simply 'waiting around'. As mentioned above, respondents from the football team stated participation in football was something they sought out in order to fill some of their free time and to provide them with routine.

The players' experience of playing in the team was also tied to routine escapism from their daily stressors.
Playing football allows them to temporarily 'switch-off' and be consumed by the 'here and now' of the game (OIliff, 2008). They can relax knowing they won't experience racism or aggression, whereas they may experience this in everyday life. Another aspect of social connectedness is seen in the formation of friendships, which carried on outside of the ASFT and the competition season.

Through the resultant social interactions the recently arrived players could connect with longer-term asylum seekers and get advice about processes, services and systems. The team manager, Sam, explains how he found the ASFT a useful resource:

I met lots of the people from different places and uhm...sometimes we would talk about our study and all of the things together as well and sometimes just like the extra help from all of the players from each other because we would talk about it and sometime we would have the sources all of the people need, maybe we can provide so just like a network. So sometime maybe someone looking for a job or someone think "oh I need a lift, [I'm] in I need something" so it's like exchange information...because everyone have a different experience of staying in Melbourne so we just try to help each other and, say, maybe I go through this process before and maybe I share the experience.

The second characteristic developed through playing with the ASFT is poly-cultural capital. Poly-cultural capital is a particular species of capital that migrants possess to successfully integrate and achieve in a new country. For Mila-Schaaf and Robinson (2010) this meant holding on to a strong sense of one's cultural identity (expressed through language, cultural practices, etc.) in the new country. We would argue that playing football offered something akin to poly-cultural capital for several reasons.

Firstly, possessing a football habitus, playing in the ASFT connected these men back to a previous identity in their home countries. We would argue that in this case football would have just as much poly-cultural capacity as would traditional dance or some other performative aspect of culture (McDonald \& Rodriguez, 2014). In this way football is more than just a diversion from oppressive conditions; it offers a return to a younger, happier sense of being. That is, that youthful memories of playing football connected them to a sense of place that often predated the conditions which caused them to flee. Importantly this sense of self, as with many dominant sports, also coincides with ideas around appropriate masculinity. Seeking asylum can be a disempowering and emasculating experience (Jaji, 2009), thus in reconnecting with something that would be considered expressive of hegemonic masculinity our participants also reinstate their manliness.

\footnotetext{
$\overline{1}$ In 2014-15 the average processing time for refugee visas from application registration to the granting of a visa was 62.7 weeks. The average processing time for Special Humanitarian Programme visas was 64.9 weeks (Australian Government, 2016).
} 
Secondly, playing football has poly-cultural capacity because of its ability to create resilience. Resilience is defined in this article as the capacity of individuals to cope with adverse life circumstances, which is constituted and enacted through the interactions between individuals and their environments (Teram \& Ungar, 2009). Several interviewees mentioned altering their lifestyle for the better as they felt a responsibility to be the best they can for the greater good of the team. Fwayo, a member of the team for two years, said he noticed a considerable change in his attitude towards himself and others since he started playing for the ASFT:

Generally, a better quality of life, you know all the free time I had sometimes I'd find myself indulging in activities that I didn't really want to be involved in, you know, like having a drink on a weekday in the afternoon, which is very unproductive and in the longer run it will affect your health...its helped me realise like, how to be responsible, because being a part of the team makes me feel like l'm committed to doing something and I try as much as I can to be there at the appropriate time and stuff, which is a test for me, you know, in terms of having responsibilities.

Fwayo had acquired considerable football capital in his youth and hence reconnecting with football through the ASFT also reconnects him to his older identity. He has used this football programme as a platform-whether consciously or not-to improve other aspects of his life. Another respondent, Rahmadan, had echoed Fwayo's sentiments. He went on to say:

About myself, there is something really important that I was monitoring every week, when I was at work I was always trying to watch myself, look after myself to be ready for the next game. So, uhm, it protects me from adopting a new lifestyle, so in terms of thinking about spending late nights or smoking or like you know bad habits, that's protected me within these three years.

The third way that football provides opportunities for the accumulation of poly-cultural capital is the way the football habitus produces a type of fluency. Football also acts as a form of expression, almost in the sense of a form of language. This is not, however, clumsy and uncertain attempts to use English, rather it is more akin to speaking one's mother tongue. Hence, even asylum seekers from different linguistic backgrounds can communicate with and through the ball.

Having developed poly-cultural capital and social connections, the success stories from the ASFT demonstrate the potential of inclusion through sport. A key component of our definition of social inclusion is the notion of reciprocity. An example of this can be seen in Azizi, who, despite his busy schedule, volunteered as a coach and prioritised his availability around the team, in his words to "give something back". After hearing Azizi's story, the CEO of Football Federation Victoria (FFV) waived Azizi's coaching course fee. In keeping with reciprocity, Azizi asked what he could do to pay the CEO back. Although there was no answer to this question, Azizi's response was running football training for the children at ASRC. The trainings began before the senior team's training session and would slightly overlap to half way through the senior team's practice. As a result, Azizi was able to attend both trainings while providing a type of "child care" service, allowing their parents to train. When the juniors' training concluded, Azizi would join the senior team and the children would simply continue playing while they waited for their fathers to finish their training. It did not take long before local children living in the area started to express interest in participating. After initially beginning with just a handful of children the trainings quickly swelled to in excess of twenty participants.

Azizi is in many ways paying back the CEO of FFV by generating an interest in football within his immediate community as well as contributing to friendships amongst children born in Melbourne and children who had arrived as asylum seekers or refugees. By 'giving back' Azizi is reciprocating to both the football community and the local community. This active participation and collaboration with his adopted society is an indication of the dynamic and creative ways inclusive practices that can evolve from something that initially starts with being able to play.

\section{Conclusion}

By foregrounding the barriers refugees and asylum seekers experience in sport and in other spheres of life, we, as researchers, tend to overlook and underplay their resilience and ability to overcome such barriers as they navigate life in a new country. In this article, we have sought to shift the analytical lens from a deficit model to a surplus, or asset-based, approach; that is, we were interested in what it is that we can learn from the stories and lived experiences of refugees and asylum seekers who do participate in a sports programme. In doing so, this article provides much-needed empirical insight that allows for a more nuanced, empirically grounded and critical appraisal of the widely held assumption in sport policy that sport participation unequivocally assists in the resettlement process of asylum seekers and refugees. Our findings point to the problematic nature of competitive mainstream sport as a site or vehicle for achieving social inclusion; however, they also show that for some asylum seekers with a 'football habitus', programmes such as ASFT can provide a meaningful space in facilitating the development of poly-cultural capital, in turn strengthening their resilience, identity and civic participation.

Further, when it comes to achieving social inclusion through sport, we outline the dissociation between Australian policy rhetoric and practice and illustrate and reflect on this through the empirical examination of a foot- 
ball programme that focuses on providing a safe and engaging space for its members. However, the programme can still elicit feelings of exclusion on occasion as the ASFT has little control over the 'othering' the team experiences, while more can also be done with regard to issues of sustainability. Nevertheless, the ASFT's 'success stories' can be attributed to the ASRC's ability to combat many of the structural and interpersonal barriers experienced by asylum seekers in sport participation, whilst the players' 'footballing habitus' and poly-cultural capital should not go unrecognised in assisting them to participate and experience various forms of social inclusion in a new country.

\section{Acknowledgements}

Many thanks to Simon Reynolds and everyone involved with the ASRC Football Team for their unwavering support throughout the research process. Thanks also to the contributions of the two reviewers.

\section{Conflict of Interests}

The authors declare no conflict of interests.

\section{References}

Amara, M., Aquilina, D., Argent, E., Betzer-Tayar, M., Green, M., Henry, I., . . . \& Taylor, J. (2004). The roles of sport and education in the social inclusion of asylum seekers and refugees: An evaluation of policy and practice in the UK. Loughborough: Loughborough University.

Australian Government. (2016). Country chapter: Australia. In Refugee resettlement handbook and country chapters (pp. 1-17). Geneva: UNHCR. Retrieved from: http://www.unhcr.org/protection/resettlement/4a2 ccf4c6/unhcr-resettlement-handbook-country-chapt ers.html

Bourdieu, P., \& Wacquant, L. (1992). An invitation to reflexive sociology. Chicago, IL: University of Chicago Press.

Cameron, M. (2013) From "queue jumpers" to "absolute scum of the earth": Refugee and organised criminal deviance in Australian asylum policy. Australian Journal of Politics and History, 59(2), 241-259.

Centre for Multicultural Youth Issues. (2007). Playing for the future: The role of sport and recreation in supporting refugee young people to 'settle well' in Australia. Melbourne: CMYI.

Clyne, M. (2005). The use of exclusionary language to manipulate opinion: John Howard, asylum seekers and the reemergence of political incorrectness in Australia. Journal of Language and Politics, 4(2), 173-196.

Collins, M., \& Haudenhuyse, R. (2015). Social exclusion and austerity policies in England: The role of sports in a new area of social polarization and inequality? Social Inclusion, 3(3), 5-18.
Cortis, N. (2009). Social inclusion and sport: Culturally diverse women's perspectives. Australian Journal of Social Issues (Australian Council of Social Service), 44(1), 91-106.

Delanty, G. (2009). Community (2nd. ed.). London: Routledge.

Department of Social Services. (2011). The people of Australia: Australia's multicultural policy. Canberra: Department of Social Services. Retrieved from https:// www.dss.gov.au/sites/default/files/documents/12 2013/people-of-australia-multicultural-policy-book let_print.pdf

Donnelly, P., \& Coakley, J. (2002). The role of recreation in promoting social inclusion. Retrieved from http://laidlawfdn.org/wp-content/uploads/2014/08/ wpsosi_2002_december_the-role-of-recreation.pdf

Evers, C. (2010). Intimacy, sport and young refugee men. Emotion, Space and Society, 3(1), 56-61.

Every, D., \& Augoustinos, M. (2007). Constructions of racism in the Australian parliamentary debates on asylum seekers. Discourse and Society, 18(4), 411-436.

Jaji, R. (2009). Masculinity on unstable ground: Young refugee men in Nairobi, Kenya. Journal of Refugee Studies, 22(2), 177-194.

Jeanes, R., O'Connor, J., \& Alfrey, L. (2014). Sport and the resettlement of young people from refugee backgrounds in Australia. Journal of Sport \& Social Issues, 39(6), 480-500.

Johns, A., Grossman, M., \& McDonald, K. (2014). 'More than a game': The impact of sport-based youth mentoring schemes on developing resilience toward violent extremism. Social Inclusion, 2(2), 57-70.

Madden, R. (2010). Being ethnographic: A guide to the theory and practice of ethnography. London: Sage.

McDonald, B., \& Rodriguez, L. (2014). 'It's our meal ticket': Pacific bodies, labour and mobility in Australia. Asia-Pacific Journal of Sport and Social Science, 3(3), 236-249.

Mila-Schaaf, K., \& Robinson, E. (2010). 'Polycultural' capital and educational achievement among NZ-born Pacific peoples. Mai Review, 1, 1-18.

Ministerial Council on Immigration and Multicultural Affairs. (2007). A national action plan to build on social cohesion, harmony and security. Canberra: DIAC.

Nathan, S., Bunde-Birouste, A., Evers, C., Kemp, L., MacKenzie, J., \& Henley, R. (2010). Social cohesion through football: A quasi-experimental mixed methods design to evaluate a complex health promotion program. BMC Public Health, 10(1), 1-12. doi:10.1186/1471-2458-10-587

Nathan, S., Kemp, L., Bunde-Birouste, A., MacKenzie, J., Evers, C., \& Shwe, T. A. (2013). “We wouldn't of made friends if we didn't come to Football United": The impacts of a football program on young people's peer, prosocial and cross-cultural relationships. BMC Public Health, 13(1), 1-16. doi:10.1186/1471-2458-13399 
Northcote, J., \& Casimiro, S. (2009). A critical approach to evidence-based resettlement policy: Lessons learned from an Australian Muslim refugee sports program. Tamara Journal of Critical Organisation Inquiry, $8(1 / 2), 173-185$.

Olliff, L. (2008). Playing for the future: the role of sport and recreation in supporting refugee young people to 'settle well' in Australia. Youth Studies Australia, 27(1), 52-60.

Palmer, C. (2009). Soccer and the politics of identity for young Muslim refugee women in South Australia. Soccer \& Society, 10. doi:10.1080/ 14660970802472643

Rich, K., Misener, L., \& Dubeau, D. (2015) “Community Cup, we are a big family": Examining social inclusion and acculturation of newcomers to Canada through a participatory sport event. Social inclusion, 3(3), 129-141.

Shilling, C. (2013). The body and social theory (3rd. ed.). London: Sage.

Spaaij, R. (2012). Beyond the playing field: Experiences of sport, social capital, and integration among So- malis in Australia. Ethnic and Racial Studies, 35(9), 1519-1538.

Spaaij, R. (2013). Cultural diversity in community sport: An ethnographic inquiry of Somali Australians' experiences. Sport Management Review, 16(1), 29-40.

Spaaij, R. (2015). Refugee youth, belonging and community sport. Leisure Studies, 34(3), 303-318.

Spaaij, R., Magee, J., \& Jeanes, R. (2014). Sport and social exclusion in global society. London: Routledge.

Spaaij, R., \& Schulenkorf, N. (2014). Cultivating safe space: Lessons for sport-for-development projects and events. Journal of Sport Management, 28(6), 633-645.

Teram, E., \& Ungar, M. (2009). Not just the master discourse: A case for holistic case studies of youth resilience. In L. Liebenberg \& M. Ungar (Eds.), Researching resilience (pp. 103-128). Toronto, ON: University of Toronto Press.

Wacquant, L. (2004) Body and soul: Notebooks of an apprentice boxer. London: Oxford University Press.

Walseth, K. (2006). Sport and belonging. International Review for the Sociology of Sport, 41(3/4), 447-464.

\section{About the Authors}
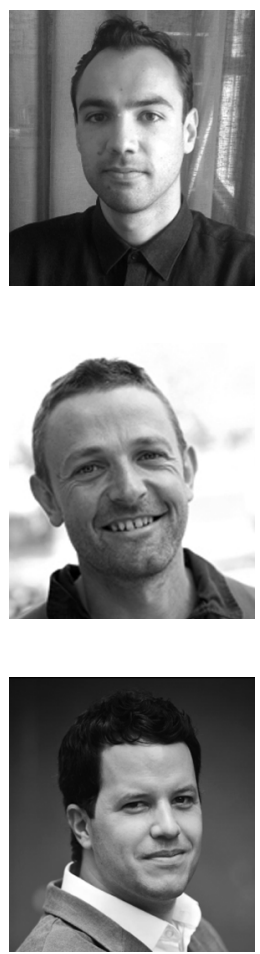

Darko Dukic graduated from Victoria University (VU) in Melbourne, Australia with a bachelor's degree in Sport Science (Human Movement) and a major in Sociology in 2016. The following year he completed an Honours research project at VU investigating the integrative aspects of football participation for people seeking asylum. Darko's academic interests are driven by his personal experiences of playing football as a refugee youth in Australia. Currently he is a sessional tutor at VU teaching Social Dimensions of Sport and Exercise.

Brent McDonald is a senior lecturer at Victoria University. His research interests include the sociology of sport and Japanese studies. His publications have focused largely on the experiences of Pacific Islander migration to Australia, Japanese education, and the (re)production of biological 'race'. He is the author of Sport in Society (McGraw Hill, 2011, with Jay Coakley and Chris Hallinan).

Ramón Spaaij is a Professor at Victoria University and the University of Amsterdam. His research interests include the sociology of sport and the sociology of terrorism. His recent books include Sport and Social Mobility: Crossing Boundaries (Routledge, 2011); Sport and Social Exclusion in Global Society (Routledge, 2014, with Jonathan Magee and Ruth Jeanes); and The Age of Lone Wolf Terrorism (Columbia University Press, 2017, with Mark S. Hamm). 